\title{
Believing that transferring more embryos will result in increased pregnancy rates: a flawed concept: a SWOT analysis
}

\author{
Michael H. Dahan *iD and Samer Tannus
}

\begin{abstract}
A belief exists that transferring multiple embryos can improve pregnancy rates. However, this concept is flawed. Multiple factors affect outcomes when transferring embryos, endometrial receptivity, and rates of aneuploidy among them. In this article, we will discuss how factors can affect outcomes at IVF that are independent of the number of embryos transferred. It is important to understand the role of accessory factors on pregnancy rates to be able to counsel patients as per the number of embryos that should be transferred. An understanding of this concept will also lead to a realistic understanding of how multiple embryo transfers may result in better cumulative pregnancy rates than a single transfer of multiple embryos. Finally, we will present a SWOT analysis diagram to help guide clinical decision-making.
\end{abstract}

Keywords: Pregnancy rates, IVF, Single embryo transfer, Endometrial receptivity, Aneuploidy

\section{Main text}

A concept exists in infertility medicine, which is that pregnancy rates increase as more embryos are transferred [1]. We often hear this concept discussed in meetings, and stated by reviewers, and is one cause of the persistently elevated rates of double embryo transfer in certain regions [2]. However, this concept is likely flawed. Recently, Gleisher et al. published an article that argues that IVF success rates peaked in 2010 and have been decreasing since then [3]. They attribute this decrease to the increased use of elective single embryo transfer among other factors [3]. Although the use of single embryo transfer can decrease outcomes per transfer [4], particularly if the embryo selected turns out to be aneuploid, overall placing back more embryos will in many cases, not improve outcomes $[5,6]$.

In some situations, the probability of an outcome occurring is based on the cumulative probability of each part, i.e., if the chance of an embryo implanting is $1 / 4$ or

\footnotetext{
* Correspondence: dahanhaim@hotmail.com

Department of Obstetrics and Gynecology, MUHC Reproductive Center, 888 Boul de Maisonneuve E \#200, Montreal, Quebec H2L 4S8, Canada
}

$25 \%$, if you transfer 4 embryos the chance of at least one implantation could be argued to be $4 \times 1 / 4$ or $100 \%$, which it is not. This statistical representation depends on each act segregating independently, or the likelihood of one thing occurring is independent of the others. An example of independent segregation is a coin toss. If you toss a coin 50 times and every time it lands heads, the chance of tails in the subsequent toss remains $50 \%$. However, biologic systems often do not segregate independently.

Pregnancy after embryo transfer is dependent on multiple factors including uterine receptivity. There are women whose endometrium is sub-receptive (low probability of implantation) [7] or possibly even unreceptive. If one genetically normal embryo is returned to such a uterus or many are transferred, the probability of pregnancy would remain very low. It is also known that there are couples that produce a low percentage or even zero percent genetically normal embryos. In this second case, the chance of pregnancy whether you return one or 4 embryos may remain extremely low, if not zero. These are factors that cannot be overcome by transferring a

\section{Springer Open}

(๑) The Author(s). 2020 Open Access This article is licensed under a Creative Commons Attribution 4.0 International License, which permits use, sharing, adaptation, distribution and reproduction in any medium or format, as long as you give appropriate credit to the original author(s) and the source, provide a link to the Creative Commons licence, and indicate if changes were made. The images or other third party material in this article are included in the article's Creative Commons licence, unless indicated otherwise in a credit line to the material. If material is not included in the article's Creative Commons licence and your intended use is not permitted by statutory regulation or exceeds the permitted use, you will need to obtain permission directly from the copyright holder. To view a copy of this licence, visit http://creativecommons.org/licenses/by/4.0/. 


\section{SET a SWAT Analysis}
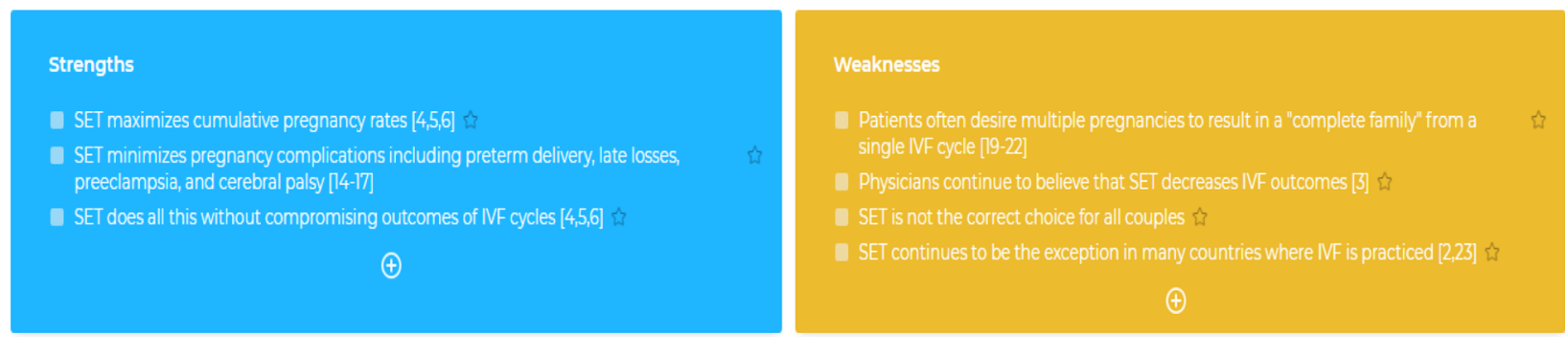

Opportunities

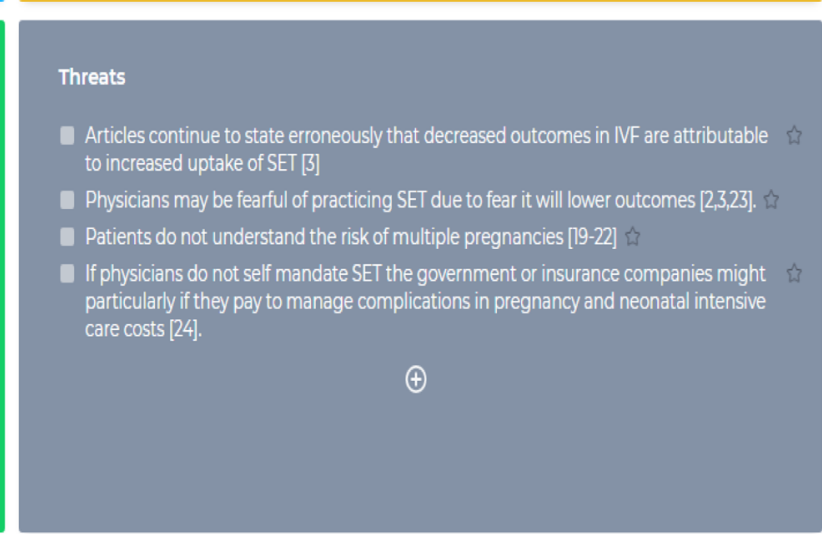

Threats

Patient education on the risk of multiple pregnancies can lead to increased adoption of SET [14-17, 19]

Patient education on the use of repetitive SET raising cumulative pregnancy rates may lead to patients favoring sequential SET over a single transfer of multiple embryos ( in the end it provides more chance of having a child) $[4,5,6]$

Clinic and international guidelines can be developed to determine the ideal candidates for SET.

Increased use of PGT-A prevents the returning to the uterus of genetically incompetent embryos with low to no chance of success [0]

Patients who succeed (higher cumulative pregnancy rates with SET) are more likely to refer other patients to your clinic.

Fig. 1 Single Embryo Transfer: A SWOT Analysis [2-4, 10, 11, 15-18, 20-25]

greater quantity of embryos. Likely, the more genetically abnormal embryos that occur, the greater probability that a subsequently tested embryo is genetically abnormal and as such the probability of one embryo affects the others, i.e., not segregating independently.

Along the same lines, likely, transferring one or two blastocysts may not affect the pregnancy rates. This has been repetitively demonstrated in multiple studies, including one by us performed in older patients, those most at risk for genetic abnormalities of embryos [5]. We also demonstrated that sequential single blastocyst transfer in women 40 years of age or older twice, as compared to a one-time double blastocyst transfer, results in a higher cumulative pregnancy rates [6]. Suggesting that endometrial dys-synchrony may be overcome in a subsequent cycle and confirming that the endometrium plays an important role in the probability of pregnancy at any given embryo transfer [6, 8-11]. In a randomized study comparing transferring a single euploid blastocyst after trophectoderm biopsy or two untested embryos, transferring two embryos resulted in similar pregnancy and ongoing pregnancy rates but much high rates of multiple gestation (54\% vs. 0\%) [12].

Unscreened single vs. double blastocyst transfer resulted in equivalent live birth rates irrespective of age in another study [13]. On the other hand, other studies have shown increasing pregnancy rates transferring two as opposed to a single blastocyst $[4,14]$. The difference between the findings of these studies likely represents the role of endometrial receptivity, transfer technique, and embryo genetics [8, 9]. A recent randomized study has brought the role of endometrial receptivity to the forefront of IVF outcomes. In a naïve patient population, screening with the endometrial receptivity assay and doing a personalized transfer resulted in significantly higher cumulative pregnancy rates (93.6\%) compared with FET $(P=0.0005)$ and fresh embryo transfer groups $(P=0.0013)[15]$. Importantly, the cumulative pregnancy rate per cycle was just south of $100 \%$ in the group screened with ERA as opposed to $80 \%$ in the other groups. This discrepancy highlights the role of endometrial receptivity on pregnancy outcomes at IVF [15].

Although transferring multiple embryos may impact the pregnancy rate per transfer, multiple pregnancies remain a risk $[4,6,14]$. We have known that this is the desired outcome for many of our patients, with the opportunity of at one time to complete their family when two children are delivered as twins. However, implications may not be well understood by patients even if consented. Our patients would not select to have a 
child with cerebral palsy. Rates of prematurity and cerebral palsy are elevated in twins as compared to singleton pregnancies [16-18]. The problem with multiple pregnancies remains the higher risk of complications, both maternal and fetal/neonatal [17-19]. These complications include higher rates of miscarriage including late second trimester miscarriages, higher rates of preterm delivery, admission to the neonatal intensive care unit, cesarean section, fetal/neonatal death, preeclampsia, gestational diabetes [17-19]. There are many situations where a single embryo transfer makes more sense than multiple embryo transfer and would not be debated. This includes when transferring a genetically normal embryo and first-time IVF in a patient under 40 years of age particularly since in young maternal age aneuploidy rates are low. When multiple pregnancies occur, reduction to a singleton pregnancy is an option [20]. However, this is usually accompanied by an increased risk of miscarriage of both fetal sacs [20]. Therefore, conceiving a singleton pregnancy from the start will clearly have a lower risk than managing a multiple pregnancy.

SWOT stands for strengths, weaknesses, opportunities, and threats. It is a mechanism to capitalize on opportunities in the market place. When evaluating the role of single embryo transfer (SET) in IVF, the following SWOT diagram was developed. It becomes clear on analyzing this diagram that there are many reasons to practice SET and that there remain issues with the adoption of SET that can be overcome. Although SET is not ideal for all patients, many patients will benefit from its adoption (Fig. 1).

In conclusion, due to the inter-dependence of biologic system variables, caution should be used when believing transferring a greater number of embryos can increase the probability of pregnancy. Instead, effort should be placed into maximizing the probability of pregnancy for each embryo and as such minimizing the number of transferred embryos. There have been significant embryological advances during the last 10 years including the use of bench top and other high-quality incubators, low oxygen tension, and time-lapse imaging that have very positive implications on embryo quality and selection and that should make SET the rule rather than exception. Multiple embryo transfer had value historically, which is less valid today. These findings when combined with lower complications for the mother and child as part of a singleton birth favor the use of single embryo transfer in most cases.

\section{Acknowledgements \\ None}

\section{Authors' contributions}

MHD conceived of and worked on the preparation of this manuscript and approved the final manuscript. ST worked on the preparation of this manuscript and approved the final manuscript.
Funding

None

Availability of data and materials

No data was used in the writing of this article.

Ethics approval and consent to participate

Not applicable

\section{Consent for publication}

Not applicable

\section{Competing interests}

The authors MHD and ST have no conflicts of interest to declare.

Received: 1 May 2020 Accepted: 22 September 2020

Published online: 14 October 2020

\section{References}

1. Aldemir O, Ozelci R, Baser E, Kaplanoglu I, Dilbaz S, Dilbaz B, Tekin OM, Aldemir $O$ et al (2020) Impact of transferring a poor quality embryo along with a good quality embryo on pregnancy outcomes in IVF/ICSI cycles: a retrospective study. Geburtshilfe Frauenheilkd 80:844-850

2. Zegers-Hochschild F, Crosby JA, Musri C, Souza MDCB, Martinez AG, Silva AA, Mojarra JM, Masoli D, Posada N, Zegers-Hochschild F et al (2020) Assisted reproductive techniques in Latin America: the Latin American Registry. JBRA Assist Reprod 24:362-378

3. Gleicher N, Kushnir VA, Barad DH (2019) Worldwide decline of IVF birth rates and its probable causes. Hum Reprod Open 3:hoz017

4. McLernon DJ, Harrild K, Bergh C, Davies MJ, de Neubourg D, Dumoulin JC, Gerris J, Kremer JA, Martikainen H, Mol BW et al (2010) Clinical effectiveness of elective single embryo transfer versus double embryo transfer-meta analysis of individual patient data from randomized trials. BMJ 341:c6945

5. Alasmari NM, Son WY, Dahan MH (2016) The effect on pregnancy and multiples of transferring 1-3 embryos in women at least 40 years old. J Assist Reprod Genet 33:1195-1202

6. Tannus S, Cohen Y, Son WY, Shavit T, Dahan MH (2017) Cumulative live birth rate following elective single blastocyst transfer compared with double blastocyst transfer in women aged 40 years and over. Reprod BioMed Online 35:733-738

7. Tan J, Kan A, Hitkari J, Taylor B, Tallon N, Warraich G, Yuzpe A, Nakhuda G (2018) The role of the endometrial receptivity array (ERA) in patients who have failed euploid embryo transfers. J Assist Reprod Genet 35:683-692

8. Dahan MH, Tan SL (2018) Variations in the endometrial receptivity assay (ERA) may actually represent test error. J Assist Reprod Genet 35:1923-1924

9. Cho K, Tan S, Buckett W, Dahan MH (2018) Intra-patient variability in the endometrial receptivity assay (ERA) test. J Assist Reprod Genet 35:929-930

10. Ruhlmann C, Molina L, Tessari G, Ruhlmann F, Tessari L, Gnocchi D, Cattaneo A, Irigoyen M, Martínez AG (2017). Optimizing the number of embryos to transfer on day 5: two should be the limit. JBRA Assist Reprod. 21;7-10.

11. Forman EJ, Hong KH, Ferry KM, Tao X, Taylor D, Levy B, Treff NR, Scott RT Jr (2013). New in vitro fertilization with single euploid blastocyst transfer: a randomized controlled trial. Fertil Steril. 100:100-7.e1.

12. Eum JH, Park JK, Kim SY, Paek SK, Seok HH, Chang EM, Lee DR, Lee WS (2016) Clinical outcomes of single versus double blastocyst transfer in fresh and vitrified-warmed cycles. Clin Exp Reprod Med 43:164-168

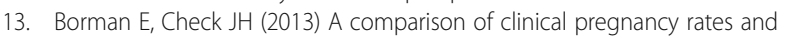
multiple gestation rates with 2 vs 3 embryos transferred with pairs matched for embryo quality. Clin Exp Obstet Gynecol 40:196-197

14. Simón C, Gómez C, Cabanillas S, Vladimirov I, Castillón G, Giles J, Boynukalin K, Findikli N, Bahçeci M, Ortega I, et al.; ERA-RCT Study Consortium Group. A 5-year multicentre randomized controlled trial comparing personalized, frozen and fresh blastocyst transfer in IVF. Reprod BioMed Online. Jun 15: S1472-6483(20)30319-9. doi: https://doi.org/10.1016/j.rbmo.2020.06.002. Online ahead of print

15. Norwitz ER, Edusa V, Park JS (2005) Maternal physiology and complications of multiple pregnancy. Semin Perinatol 29:338-348

16. Korb D, Schmitz T, Seco A, Le Ray C, Santulli P, Goffinet F, Hum D-TC (2020) Increased risk of severe maternal morbidity in women with twin pregnancies resulting from oocyte donation. Reprod. 35:1922-1932 
17. Korb D, Schmitz T, Seco A, Goffinet F, Deneux-Tharaux C, JUmeaux MODe d'Accouchement (JUMODA) study group and the Groupe de Recherche en Obstétrique et Gynécologie (GROG) (2020) Risk factors and high-risk subgroups of severe acute maternal morbidity in twin pregnancy: a population-based study. PLoS One 15:e0229612

18. Makhseed M, Al-Sharhan M, Egbase P, Al-Essa M, Grudzinskas JG (1998) Maternal and perinatal outcomes of multiple pregnancy following IVF-ET. Int J Gynaecol Obstet 61:155-163

19. Zemet R, Haas J, Bart Y, Barzilay E, Shapira M, Zloto K, Hershenson R, Weisz B, Yinon Y, Mazaki-Tovi S, Lipitz S (2020) The earlier the better or the later the better: optimal timing of fetal reduction from twins to singleton Ultrasound Obstet Gynecol. https://doi.org/10.1002/uog.22119 Online ahead of print

20. La Sala GB, Morini D, Gizzo S, Nicoli A, Palomba S (2016) Two consecutive singleton pregnancies versus one twins pregnancy as preferred outcome of in vitro fertilization for mothers and infants: a retrospective case-control study. Curr Med Res Opin 32:687-692

21. Leese B, Denton J (2010) Attitudes towards single embryo transfer, twin and higher order pregnancies in patients undergoing infertility treatment: a review. JHum Fertil (Camb) 13:28-34

22. Højgaard A, Ottosen LD, Kesmodel U, Ingerslev HJ (2007) Patient attitudes towards twin pregnancies and single embryo transfer - a questionnaire study. Hum Reprod 22:2673-2678

23. Newton CR, McBride J, Feyles V, Tekpetey F, Power S (2007) Factors affecting patients' attitudes toward single- and multiple-embryo transfer. Fertil Steril 87:269-278

24. Okohue JE, Onuh SO, Ikimalo JI, Wada I (2010) Patients' preference for number of embryos transferred during IVF/ICSI: a Nigerian experience. J Clin Pract 13:294-297

25. Shaulov T, Belisle S, Dahan MH (2015) Public health implications of a North American publicly funded in vitro fertilization program; lessons to learn. J Assist Reprod Genet 32:1385-1393

\section{Publisher's Note}

Springer Nature remains neutral with regard to jurisdictional claims in published maps and institutional affiliations.

\section{Submit your manuscript to a SpringerOpen ${ }^{\circ}$ journal and benefit from:}

- Convenient online submission

- Rigorous peer review

- Open access: articles freely available online

- High visibility within the field

- Retaining the copyright to your article

Submit your next manuscript at $\boldsymbol{\nabla}$ springeropen.com 